\title{
A Study of Galactose Intolerance in Human and Rat Liver In Vivo by ${ }^{31} \mathrm{P}$ Magnetic Resonance Spectroscopy
}

\author{
BELLA KALDERON, ${ }^{1}$ RUTH M. DIXON, BHEESHMA RAJAGOPALAN, \\ PETER W. ANGUS, ${ }^{2}$ ROLF D. OBERHAENSLI, ${ }^{3}$ JANE E. COLLINS, ${ }^{4}$ JAMES V. LEONARD, AND \\ GEORGE K. RADDA \\ Medical Research Council Biochemical and Clinical Magnetic Resonance Unit, John Radcliffe Hospital, \\ Oxford OX3 9DU, United Kingdom [B.K., R.M.D., B.R., P.W.A., R.D.O., G.K.R.]; and Department of Child \\ Health, Institute of Child Health, London WCIN 1EH, United Kingdom [J.E.C., J.V.L.]
}

\begin{abstract}
An oral load of $20 \mathrm{mg} / \mathrm{kg}$ galactose produces significant changes in the ${ }^{31} \mathrm{P}$ magnetic resonance spectrum of the liver of a galactosemic patient. The peak at $5.2 \mathrm{ppm}$ (which includes inorganic phosphate and galactose-1-phosphate) increased on two occasions to about twice its original size $60 \mathrm{~min}$ after galactose administration. An oral load of $10 \mathrm{mg} / \mathrm{kg}$ galactose given to a second patient produced no discernible changes at $30 \mathrm{~min}$. We have also used an animal model of galactose intolerance, in which galactose metabolism in rats was blocked by the acute administration of ethanol. Studies in vivo and in vitro showed that the increase in the peak at $5.2 \mathrm{ppm}$ was largely due to galactose-1-phosphate. We have shown in this preliminary study that small amounts of galactose can produce significant elevation of hepatic galactose-1-phosphate, which can be detected by ${ }^{31} \mathrm{P}$ magnetic resonance spectroscopy. (Pediatr Res 32: 39-44, 1992)
\end{abstract}

\section{Abbreviations}

MRS, magnetic resonance spectroscopy

MR, magnetic resonance

$P_{i}$, inorganic phosphate

UDP, uridine diphosphate

Galactosemia is an autosomal recessive disorder caused by a deficiency of the enzyme UDPglucose: $\alpha$-D-galactose-1-phosphate uridylyltransferase (EC 2.7.7.12) (Fig. 1) (1). In infancy, ingestion of galactose by patients with galactosemia causes liver disease, cataract, and failure to thrive, but with strict exclusion of galactose there is rapid improvement with resolution of the liver disease and normal growth. The diagnosis of galactosemia is normally confirmed by measuring the enzyme activity in red blood cells, but the major site of galactose metabolism is the liver (2). The liver damage is thought to be caused by accumulation of metabolites of galactose, although the exact mechanism is

Received January 14, 1991; accepted November 30, 1991.

Correspondence: Dr. Ruth M. Dixon, MRC Biochemical and Clinical Magnetic Resonance Unit, John Radcliffe Hospital, Oxford, OX3 9DU, U.K.

Supported by the Medical Research Council and the Department of Health.

'Present address: Department of Biochemistry, The Hebrew University, Hadassah Medical School, Jerusalem, Israel.

${ }^{2}$ Present address: Austin Hospital, Studley Road, Heidelberg 3084, Victoria, Australia.

${ }^{3}$ Present address: Department of Biophysical Chemistry, Biozentrum Basel Klingelberg Strasse 70, CH4056, Switzerland.

${ }_{4}^{4}$ Present address: Department of Paediatrics, Guys Hospital, London, SE1 9RT, unclear (1). We have used MRS of the liver to determine the fate of galactose noninvasively in this disorder. We have previously shown in another hereditary disorder, fructose intolerance, that it is possible to detect noninvasively the effects of a small amount of fructose on the liver by means of ${ }^{31} \mathrm{P}$ MRS (3). In this study, we show that small amounts of oral galactose produce significant changes in ${ }^{31} \mathrm{P}$ MR spectra of the liver. In an animal model in which galactose metabolism is partially blocked, we show that the changes seen in the patient are probably due to the accumulation of galactose-1-phosphate. This model uses acute administration of ethanol, which inhibits UDPglucose-4-epimerase (EC 5.1.3.2) (Fig. 1) by increasing the $\mathrm{NADH} / \mathrm{NAD}^{+}$ratio in the liver. Although this is not the enzyme that is deficient in galactosemia, its inhibition blocks the usual pathway of galactose metabolism, leading to an accumulation of galactose-1-phosphate and UDPgalactose $(4,5)$.

\section{MATERIALS AND METHODS}

Patients. Two patients with galactosemia were studied (Table 1). The patients or their guardians gave informed consent to the study, which was approved by the local ethics committee. Both were on a strict galactose-free diet and were studied after an overnight fast. The two patients were well controlled, with red blood cell galactose-1-phosphate concentrations usually within the normal range $(<0.57 \mu \mathrm{mol} / \mathrm{g} \mathrm{Hb})$.

$M R S .{ }^{31} \mathrm{P}$ MR spectra were obtained with a 1.9-tesla, $60-\mathrm{cm}$ bore superconducting magnet operating at $32.7 \mathrm{MHz}$ for phosphorus. The patient lay prone with her liver positioned over a 8$\mathrm{cm}$ diameter surface coil. The spectra were localized with a fieldprofiling technique (6). This method (now largely superseded by more accurate localization strategies) sometimes gives rise to spectra with a contribution from overlying skeletal muscle (as evidenced by the phosphocreatine peak in Fig. 2). From the known phosphocreatine/ATP ratio in muscle under these acquisition conditions, we estimate that less than $10 \%$ of the nucleoside triphosphate peaks in the spectrum can be from muscle, and much smaller proportions of the phosphomonoester, $P_{i}$, and phosphodiester peaks. The interpulse delay was $1 \mathrm{~s}$, with a pulse angle of $90^{\circ}$ in the liver. Patient 1 was given $20 \mathrm{mg} / \mathrm{kg}$ galactose orally and patient 2 was given $10 \mathrm{mg} / \mathrm{kg}$. Spectra were collected from patient 1 at 5 -min intervals before and for up to $60 \mathrm{~min}$ after the administration of galactose. In a second study on this patient, brain and liver spectra were collected. After the administration of $20 \mathrm{mg} / \mathrm{kg}$ galactose, brain spectra were collected for $40 \mathrm{~min}$, followed by a final liver spectrum at $60 \mathrm{~min}$. In the study on patient 2 , spectra were collected before and at 30 min after the galactose dose. Results are expressed as a percentage of the mean pregalactose peak areas. 
Animal study. In the animal study, male Wistar rats (200-300 g) were fasted for $24 \mathrm{~h}$, with free access to water. The care of the animals at all times conformed to the Home Office guidelines for the care and use of laboratory animals. The rats were anesthetized with nitrous oxide and halothane and were nephrectomized, and the femoral vein was cannulated. Ethanol (100-150 $\mathrm{mg} / 100 \mathrm{~g}$ body weight) was infused via the cannula, followed after $15 \mathrm{~min}$ by galactose $(45-100 \mathrm{mg} / 100 \mathrm{~g})$. In a control group, saline replaced the ethanol. ${ }^{31} \mathrm{P} \mathrm{MR}$ spectra were obtained at 1.9 tesla at 15 -min intervals throughout the experiment by means of a surface coil inserted between the lobes of the surgically exposed liver. Twenty to $30 \mathrm{~min}$ after infusion of galactose, the livers were removed and freeze-clamped.

The frozen livers were ground into a powder under liquid nitrogen and extracted with $6 \%$ perchloric acid (about $3 \mathrm{~mL} / \mathrm{g}$ of liver). The extracts were centrifuged, neutralized with $\mathrm{KOH}$, freeze-dried, and dissolved in EDTA $(15 \mathrm{mM})$ at $\mathrm{pH}$ 8.5. The solutions were studied by ${ }^{31} \mathrm{P}$ MRS at $121 \mathrm{MHz}$. Spectra were obtained with a $45^{\circ}$ pulse and an interpulse delay of $5 \mathrm{~s}$, with broad-band proton decoupling (with a WALTZ sequence) during acquisition. Compounds were identified by their chemical shifts in comparison with published values, by their $\mathrm{pH}$ titration behavior, and by adding authentic samples of suspected compounds. Peak areas were quantified with the spectrometer's integration routine, and metabolite levels were expressed as percentages of total acid-extractable phosphorus. Chemical shifts are relative to phosphocreatine at $0 \mathrm{ppm}$, with glycerophosphocholine at $2.9 \mathrm{ppm}$ acting as an internal chemical shift standard.

\section{RESULTS}

Patients. Patient 1 showed an initially normal ${ }^{31} \mathrm{P}$ MR liver spectrum (all metabolite ratios being within $2 \mathrm{SD}$ of the control mean), whereas patient 2 had a $\mathrm{P}_{\mathrm{i}}$ /ATP ratio higher than the normal range (Table 1). Control data from subjects of this age group are not available, but our studies of children aged 5 and 6 $\mathrm{y}$ with other conditions showed liver spectra indistinguishable

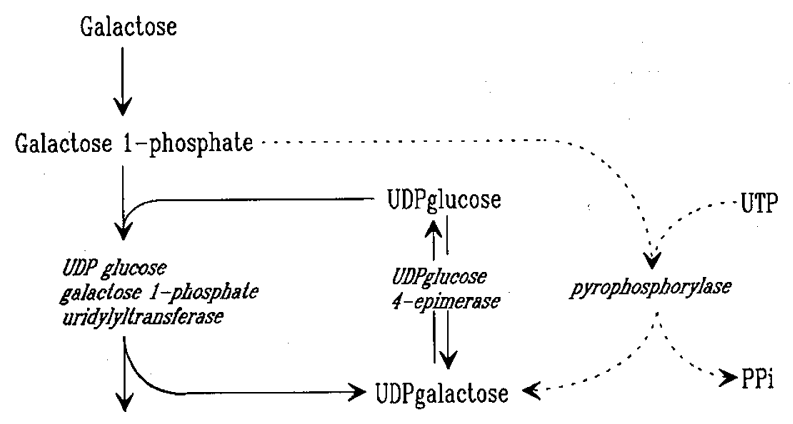

Glucose 1-phosphate

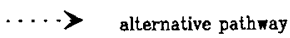

Fig. 1. Galactose metabolism in the mammalian liver. UTP, uridine triphosphate; $P P i$, pyrophosphate. from those of adults. Spectra from the livers of neonates are different from the adult spectra in that the phosphomonoester signals are relatively larger (7).

The effect of administration of $20 \mathrm{mg} / \mathrm{kg}$ galactose to patient 1 on her ${ }^{31} \mathrm{P}$ MR liver spectrum is shown in Figure 2. There was an increase in the intensity of the peak at $5.2 \mathrm{ppm}$, which includes $P_{i}$ and galactose-1-phosphate, and the time course of the changes is shown in Figure 3. The area of the peak at $5.2 \mathrm{ppm}$ reached $150 \%$ of its initial value after $30 \mathrm{~min}$, rising to $180 \%$ at the end of the study. The areas of the ATP peaks were unchanged over this time. In the second study on the same patient, normal brain and liver ${ }^{31} \mathrm{P}$ MR spectra were again obtained. After the administration of $20 \mathrm{mg} / \mathrm{kg}$ galactose, the brain spectra were unchanged over $40 \mathrm{~min}$. A liver spectrum obtained $60 \mathrm{~min}$ after the galactose dose showed an increase in the peak at $5.2 \mathrm{ppm}$ to $223 \%$ of its original area. Patient 2 , given $10 \mathrm{mg} / \mathrm{kg}$ galactose, showed no significant changes in a spectrum obtained $30 \mathrm{~min}$ after the dose. A smaller dose was chosen for this patient in view of her age (7 y) and the large changes seen in patient 1 .

Animal study. The animal study in vivo showed similar but less marked changes in animals treated with ethanol and galactose compared with the patient (Fig. 4). The peak at $5.2 \mathrm{ppm}\left(\mathrm{P}_{\mathrm{i}}\right.$ and galactose- 1 -phosphate) increased by $20 \pm 3 \%$ relative to before treatment, but the ATP $\beta$-P declined over the same time course (Table 2). An increase in the phosphomonoester region was seen in some animals after ethanol administration, before infusion of galactose. The saline and galactose-treated animals showed no significant changes.

The spectra of extracts (Fig. 5 and Table 3 ) show that galactose1-phosphate (in the $P_{i}$ region) and UDPgalactose (in the ATP $\alpha$ $P$ region) were both increased in the ethanol and galactose-treated animals to about 2.5 times the amounts found in the saline and galactose-treated animals, whereas a slight decrease in ATP and increase in $\mathrm{P}_{\mathrm{i}}$ were seen in both groups, compared with untreated controls. Neither galactose-1-phosphate nor UDPgalactose was detectable in untreated (fasted) rat liver extracts. The spectra of extracts show that the ratio of UDPgalactose to galactose-1phosphate was about $1.5: 1$, both in the ethanol and galactosetreated group and in the saline and galactose-treated animals, suggesting that inhibition of UDPglucose-4-epimerase by ethanol does not alter the product-to-substrate ratio of UDPglucose:galactose-1-phosphate uridylyltransferase, which is the previous enzyme in the pathway. The epimerase reaction is considered to be near equilibrium in the liver. In vitro studies of UDPglucose-4-epimerase have shown the ratio of UDPglucose to UDPgalactose to be about 3:1 at equilibrium (4), but this ratio is shifted toward UDPgalactose when the epimerase is inhibited. We found that the UDPglucose:UDPgalactose ratio altered from about 3:1 in the saline-treated rat liver to about 1:5 in the ethanol and galactose-treated animals (Fig. 5), thus our results are consistent with inhibition of the epimerase.

This is further supported by the ratios of $s n$-3-glycerol phosphate, phosphoenol pyruvate and 3-phosphoglycerate measured in the liver extracts (Fig. 6 and Table 4). Ethanol inhibits UDPglucose-4-epimerase by altering $\mathrm{NADH} / \mathrm{NAD}^{+}$ratios, NADH being a potent inhibitor $(5,8)$. A higher cytosolic NADH/NAD ${ }^{+}$

Table 1. Details of patients

\begin{tabular}{|c|c|c|c|c|c|}
\hline . & Sex & Age (y) & $\begin{array}{l}\text { Red blood cell ur- } \\
\text { idylyltransferase } \\
(\mu \mathrm{mol} \text { substrate } \\
\text { converted/h/g Hb) }\end{array}$ & $\begin{array}{c}\text { Red blood cell galac- } \\
\text { tose- } 1-\text { phosphate } \\
(\mu \mathrm{mol} / \mathrm{g} \mathrm{Hb})\end{array}$ & $\begin{array}{c}\text { Hepatic } \\
\mathrm{P}_{\mathrm{i}} / \mathrm{ATP} \\
\text { (MRS ratio) }\end{array}$ \\
\hline $\begin{array}{l}\text { Patient } 1 \\
\quad \text { 1st MRS study } \\
\text { 2nd MRS study } \\
\text { Patient } 2 \\
\text { Normal levels } \\
\text { Controls (for MRS study) }\end{array}$ & $\mathrm{F}$ & $\begin{array}{c}7 \\
20-45\end{array}$ & $\begin{array}{r}0.2 \\
0 \\
>18\end{array}$ & $\begin{array}{r}0.12 \\
0.60 \\
0.69 \\
<0.57\end{array}$ & $\begin{array}{l}0.87 \\
0.75 \\
1.06 \\
0.64( \pm 0.3)^{*}\end{array}$ \\
\hline
\end{tabular}

$*$ Mean $\pm 2 \mathrm{SD} ; n=23$. 

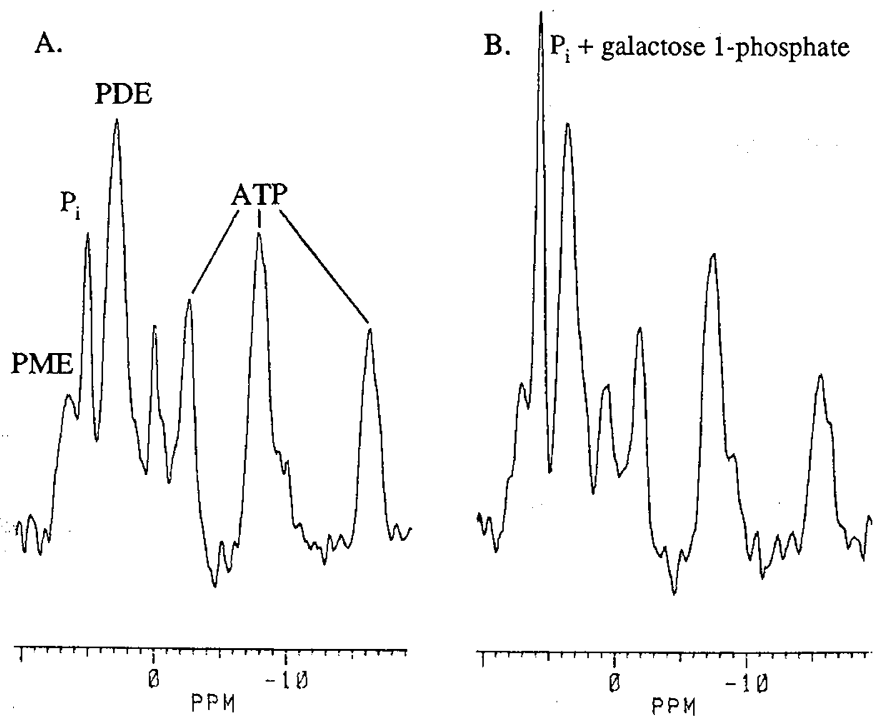

Fig. 2. ${ }^{3 t} \mathrm{P} \mathrm{MR}$ spectra in vivo of the liver of a galactosemic patient before $(A)$ and after $(B)$ administration of $20 \mathrm{mg} / \mathrm{kg}$ galactose. The peak at $0 \mathrm{ppm}$ is from phosphocreatine in overlying muscle. The peaks labeled ATP contain contributions from other nucleoside triphosphates and diphosphates as can be seen in the extract spectra in Figure 5. The signal from the $\beta$-phosphate of ATP at -16 ppm contains about $10 \%$ guanosine 5'-triphosphate. $P M E$, phosphomonoester, $P D E$, phosphodiester.

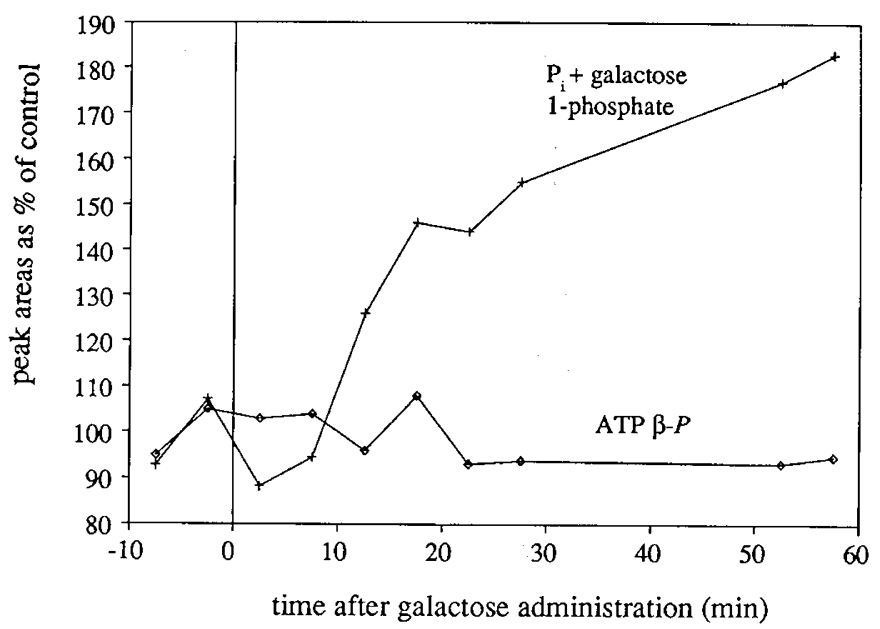

Fig. 3. Relative peak areas in the patient's liver spectrum after the administration of galactose (mean initial values set to $100 \%$ ).
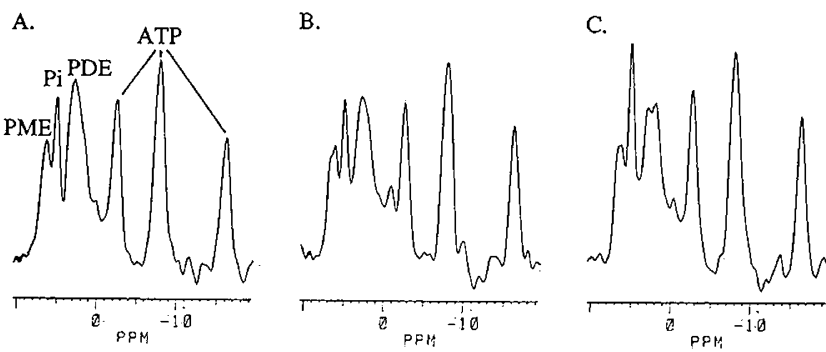

Fig. 4. ${ }^{31} \mathrm{P}$ MR spectra at $32 \mathrm{MHz}$ of fasted rat liver in vivo before treatment $(A)$, and after sequential infusions of ethanol $(B)$, and galactose $(C)$. All spectra are from a sequence of experiments in a single animal. Details of MRS are in the text. The peaks labeled ATP contain contributions from other nucleoside triphosphates and diphosphates, as can be seen in the extract spectra in Figure 5. The signal from the $\beta$-phosphate of ATP at -16 ppm contains about $10 \%$ guanosine triphosphate. PME, phosphomonoester; $P i$, inorganic phosphate; $P D E$, phosphodiester.
Table 2. Animal study: in vivo hepatic metabolite levels as \% of pretreatment values [mean (SEM)]*

\begin{tabular}{ccccc}
\hline Treatment & $n$ & PME & $P_{\mathrm{i}}$ & ATP $\beta-\mathrm{P}$ \\
\hline Ethanol + galactose & 7 & 114 & $119 \dagger$ & $87 \dagger$ \\
& & $(6)$ & $(3)$ & $(4)$ \\
Saline + galactose & 4 & 103 & 97 & 98 \\
& & $(1)$ & $(3)$ & $(1)$ \\
\hline
\end{tabular}

* PME, phosphomonoester; ATP $\beta$-P, ATP $\beta$-phosphate.

$\dagger p<0.01$ compared to before treatment (paired $t$ test).

ratio would be expected to give increased levels of $s n$-3-glycerol phosphate and decreased levels of phosphoenol pyruvate and 3phosphoglycerate by the effect of this ratio on the equilibria of glycerol phosphate dehydrogenase and glyceraldehyde-3-phosphate dehydrogenase. The results in Table 4 confirm that the ethanol-treated animals indeed had a markedly raised 3-glycerol phosphate/3-phosphoglycerate ratio, and therefore the increased $\mathrm{NADH} / \mathrm{NAD}^{+}$ratio may be inferred. The increase in $s n-3-$ glycerol phosphate may explain the change in the phosphomonoester region of the spectra in vivo after the administration of ethanol.

\section{DISCUSSION}

This study shows that in galactosemia, a small oral galactose load can produce large changes in the ${ }^{31} \mathrm{P}$ MR spectra of the liver. The metabolite ratios in the unstressed liver were normal in one of the patients, whereas the second patient had a $\mathrm{P}_{\mathrm{i}} / \mathrm{ATP}$ ratio just above the normal range, the other metabolite ratios being normal. There seemed to be little correlation between resting red cell galactose-1-phosphate levels and liver $\mathrm{P}_{\mathrm{i}} / \mathrm{ATP}$ ratios (Table 1).

An oral galactose load of $20 \mathrm{mg} / \mathrm{kg}$ given to patient 1 was followed by a rise in the region of the ${ }^{31} \mathrm{P}$ MR spectrum that includes $P_{i}$ and galactose-1-phosphate, following the time course shown in Figure 3. It is likely that most of the increase in this peak was due to accumulation of galactose-1-phosphate, which in galactosemic patients is not converted to glucose-1-phosphate. In the MR spectrum in vivo, however, the galactose-1-phosphate and $P_{i}$ signals are too close together to be resolved. There may be a contribution from $P_{j}$ to this signal; Isselbacher (9) has proposed an alternative pathway (Fig. 1) for the conversion of galactose-1-phosphate to UDPgalactose, with the release of pyrophosphate, further hydrolyzed to $P_{i}$. The activity of the pyrophosphorylase (galactose-1-phosphate uridylyltransferase EC 2.7.7.10) in vivo, however, is thought to be quite low, so the release of $P_{i}$ from this reaction is unlikely to be a major contributor to the increase seen in the peak in vivo. In a second study, we monitored changes in the patient's brain over the same time course. Spectra were collected from her brain and liver before the administration of $20 \mathrm{mg} / \mathrm{kg}$ galactose, then brain spectra were collected for $40 \mathrm{~min}$ after the dose. No changes were observed during this time. The patient was then repositioned, and a liver spectrum was obtained $(60 \mathrm{~min}$ after the galactose dose). The peak at $5.2 \mathrm{ppm}$ had increased to a similar extent as it had at $60 \mathrm{~min}$ in the previous study.

The large change seen in the first patient's liver spectrum after $20 \mathrm{mg} / \mathrm{kg}$ galactose suggested that this dose could be deleterious in view of the possible toxicity of galactose-1-phosphate, particularly in younger patients. We were also interested in determining the sensitivity of the method at lower galactose loads. We therefore administered only $10 \mathrm{mg} / \mathrm{kg}$ galactose orally to patient 2 . No changes were seen in her ${ }^{31} \mathrm{P}$ MR spectrum at $30 \mathrm{~min}$ after the dose. The reasons for this are unclear, but it was not possible to follow the complete time course in this patient, and so a transient change may have been missed.

In fructosemic patients, the chemical shifts of fructose-1-phosphate and $P_{i}$ are sufficiently different for them to be distinguished and separately quantified in vivo (3). Because this was not pos- 

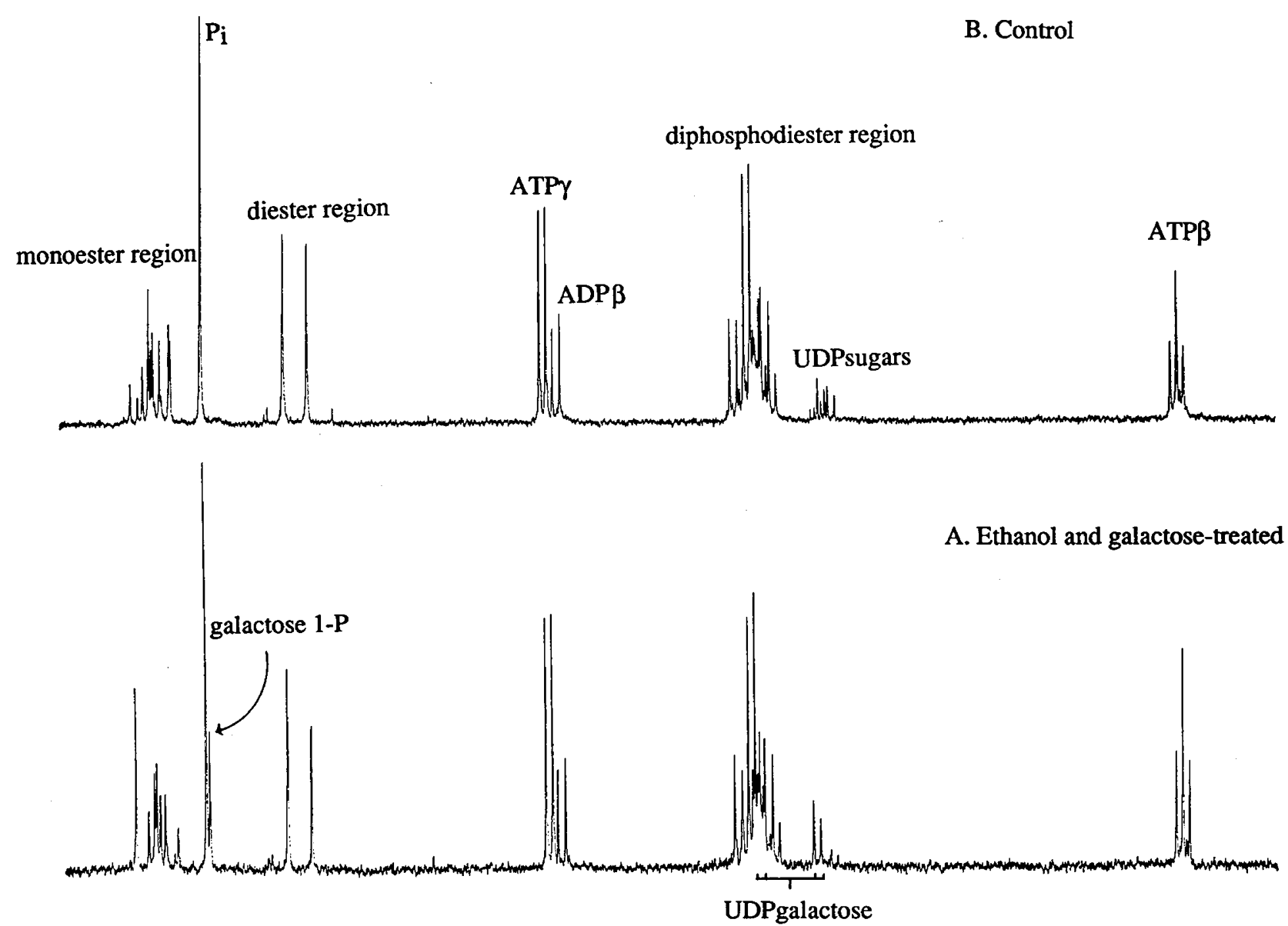

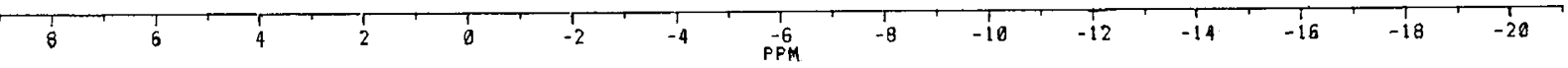

Fig. 5. ${ }^{31} \mathrm{P}$ MR spectra of the perchloric acid extracts of fasted rat liver at $121 \mathrm{MHz}$. $A$, Ethanol and galactose-treated; $B$, control. Sweep width $6000 \mathrm{~Hz}$, transformed with gaussian window (time constant $1 \mathrm{~s}$ ).

Table 3. Animal study: in vitro levels as \% of total phosphoruscontaining metabolites [mean (SEM)]*

\begin{tabular}{lccccc}
\hline \multicolumn{1}{c}{ Treatment } & $n$ & $\mathrm{P}_{\mathrm{i}}$ & Galactose-1-P & ATP & UDPgalactose \\
\hline None & 11 & 8.5 & ND & 10.9 & ND \\
& & $(0.6)$ & & $(0.3)$ & \\
Saline + galactose & 4 & 9.2 & 0.9 & 9.3 & 1.9 \\
& & $(1.4)$ & $(0.1)$ & $(0.8)$ & $(0.1)$ \\
Ethanol + galactose & 11 & 10.2 & $2.1 \dagger$ & 8.6 & $3.1 \dagger$ \\
& & $(0.5)$ & $(0.2)$ & $(0.5)$ & $(0.2)$ \\
\hline
\end{tabular}

* Galactose-1-P, galactose-1-phosphate; ND, not detectable.

$\dagger p<0.01$ compared to saline + galactose administration and compared to no treatment.

sible in the galactosemic patients, we studied an animal model to elucidate the changes in $P_{i}$ and galactose-1-phosphate. Rats were rendered galactose intolerant by inhibiting the epimerase with ethanol. High-resolution spectra of liver extracts revealed separate peaks for galactose-1-phosphate and $P_{i}$ (Figs. 5 and 6). The increase in the $P_{i}$ region was found to be due almost entirely to galactose-1-phosphate, with only a small contribution from an increase in $\mathrm{P}_{\mathrm{i}}$ (Table 3). The small decrease in ATP compared with controls was not statistically significant, although there was a small but significant decrease in ATP in the spectra in vivo after ethanol and galactose treatment. The relative galactose load was up to 50 times greater than that in the human study.

If the changes after galactose treatment in the rat are similar to those in the human liver, then it is possible to explain the relative absence of hyperuricemia and clinical gout in patients with galactose intolerance compared to patients with either fructose intolerance or glycogen storage disease. In fructose intolerance, fructose leads to significant depletion of ATP (partly due to trapping as fructose-1-phosphate) and large swings in $P_{i}$. Depletion of ATP activates the adenylate kinase reaction (2 ADP $\rightarrow$ ATP + AMP), increasing AMP in an attempt to reestablish ATP levels. Swings in $P_{i}$ concentration are known to activate rate-limiting enzymes in uric acid production (phosphoribosylpyrophosphate synthetase is activated by high $P_{i}(10)$, whereas AMP deaminase is activated by low $P_{i}(11)$, both of which can lead to increased purine production and and therefore to increased serum urate). Patients with glycogen storage disease type I show depletion of ATP and $P_{i}$ during fasting and an increase in $P_{i}$ after glucose $(10,12)$. Thus, in both fructosemia and type $1 \mathrm{~A}$ glycogen storage disease, the precursor for uric acid production (i.e., AMP) is present and there is an increase in enzyme activity, so an increase in serum urate can be expected. In galactosemia, the data from rats suggest that there is minimal increase in $\mathrm{P}_{\mathrm{i}}$, and the human data shows no decrease in ATP, so that the metabolite sequelae are not the same as in fructose intolerance or glycogen storage disease. The reasons for the differences between the ATP levels in these conditions are not clear. It is difficult to understand why the hepatocytes cannot rephosphorylate ADP in patients with fructosemia or glycogen storage disease if they can do so in patients with galactosemia.

In conclusion, oral galactose produces large changes in the ${ }^{31} \mathrm{P}$ MR spectra of the liver that are likely to be due to accumulation of galactose-1-phosphate. These changes were not seen in the brain over the same time course, confirming the importance of 

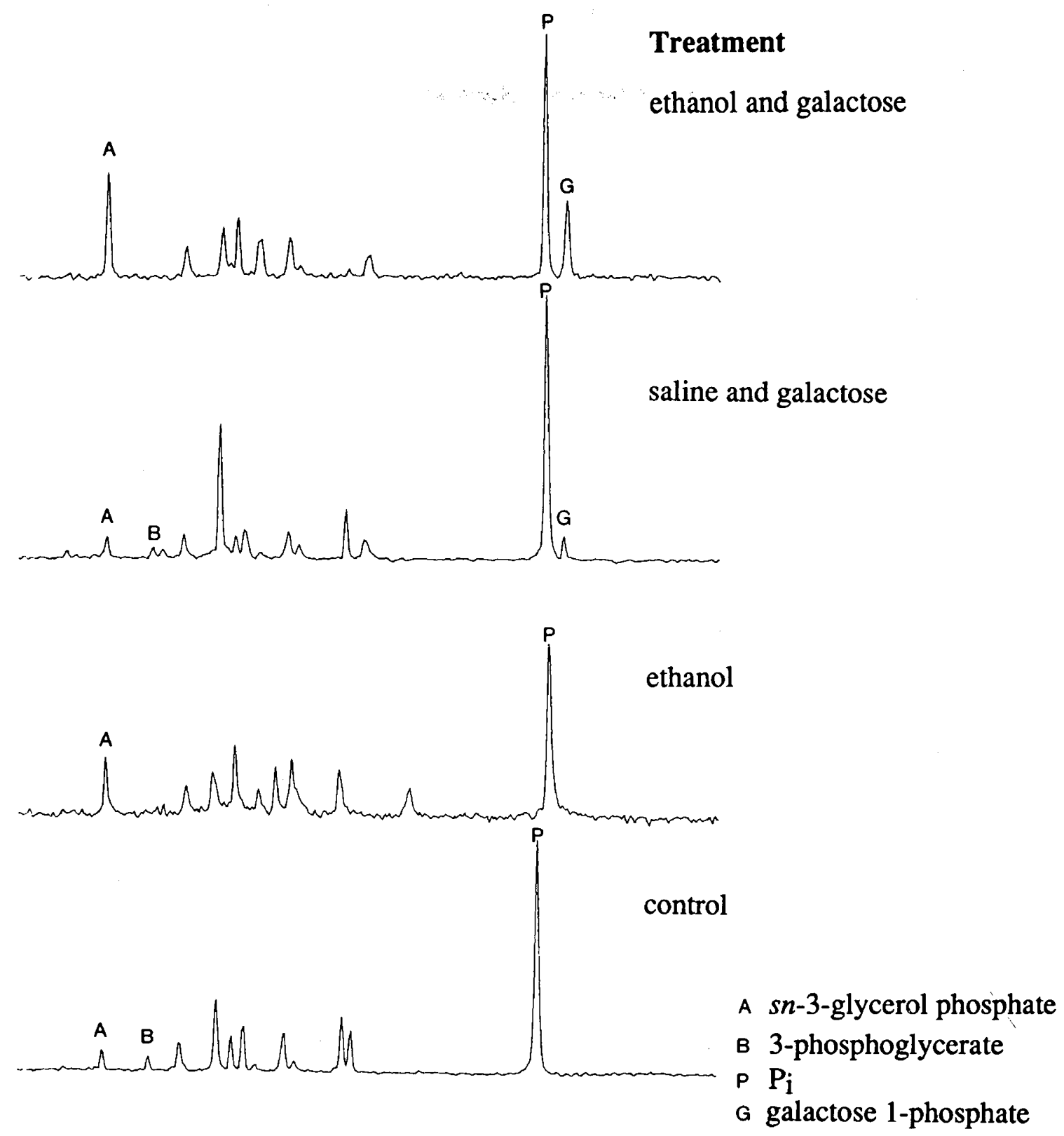

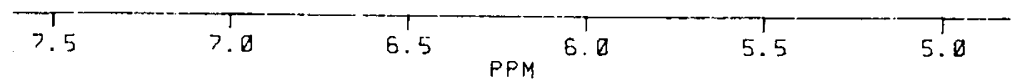

Fig. 6. Expansion of phosphomonoester and $\mathrm{P}_{\mathrm{i}}$ regions of extract spectra. Slight differences in the positions of peaks are due to $\mathrm{pH}$ variations.

Table 4. Animal study: in vitro levels of intermediary phosphorus-containing metabolites, as \% of total phosphoruscontaining metabolites [mean (SEM)]

\begin{tabular}{lcccc}
\hline \multicolumn{1}{c}{ Treatment } & $n$ & $\begin{array}{c}s n \text {-3-Glycerol } \\
\text { phosphate }\end{array}$ & $\begin{array}{c}\text { 3-Phospho } \\
\text { glycerate }\end{array}$ & $\begin{array}{c}\text { Phosphoenol } \\
\text { pyruvate }\end{array}$ \\
\hline Fasted control & 11 & 1.1 & 0.5 & 0.2 \\
& & $(0.3)$ & $(0.1)$ & $(0.1)$ \\
Saline + galactose & 4 & 1.6 & 0.5 & 0.2 \\
& & $(0.3)$ & $(0.1)$ & $(0.1)$ \\
Ethanol + galactose & 11 & 3.4 & $<0.1$ & $<0.1$ \\
& & $(0.3)$ & & \\
\hline
\end{tabular}

the liver as the initial site of galactose metabolism. Thus, this preliminary study suggests that ${ }^{31} \mathrm{P} \mathrm{MR}$ spectroscopy can be used to monitor time-dependent changes in the liver of galactosemic patients, despite the fact that the changes were found in only one of two patients. The reason for this was either the smaller dose given to the second patient or the fact that the liver spectrum was only collected at $30 \mathrm{~min}$ after the galactose dose and a transient change could have been missed. In contrast to measurements of red blood cell galactose-1-phosphate, which are, of course, much more readily available, our studies follow the changes in metabolite levels in the liver that are thought to lead directly to the toxic effects of galactose. ${ }^{31} \mathrm{P}$ MRS is relatively insensitive for detecting changes in galactosemia, but further studies in newly diagnosed patients may help to elucidate the relation between red blood cell galactose-1-phosphate and hepatic levels of this metabolite.

\section{REFERENCES}

1. Segal S 1989 Disorders of galactose metabolism. In: Scriver CR, Beandet AL Sly WS, Valie D (eds) The Metabolic Basis of Inherited Disease, 6th Ed. McGraw Hill, New York 
2. Kalckar HM, Anderson EP, Isselbachar KJ 1956 Galactosemia, a congenital defect in a nucleotide transferase. Biochim Biophys Acta 20:262-269

3. Oberhaensli RD, Rajagopalan B, Taylor DJ, Radda GK, Collins JE, Leonard JV, Schwartz H, Herschkowitz N 1987 Study of hereditary fructose intolerance by ${ }^{31} \mathrm{P}$ magnetic resonance spectroscopy. Lancet 2:931-934

4. Maxwell ES 1957 The enzymatic interconversion of uridine diphosphogalactose and uridine diphosphoglucose. J Biol Chem 229:139-151

5. Keiding S 1974 Effect of ethanol and fructose on galactose elimination in the rat. Scand J Clin Invest 34:91-96

6. Oberhaensli RD, Galloway GJ, Taylor DJ, Bore PJ, Radda GK 1986 Assessment of human liver metabolism by phosphorus-31 magnetic resonance spectroscopy. Br J Radiol 59:695-699

7. Iles RA, Cox IJ, Bell JD, Dubowitz LMS, Cowan F, Bryant DJ 1990 31P Magnetic resonance spectroscopy of the pediatric liver. NMR in Biomedicine 3:90-94
8. Keiding S, Vinterby A 1976 Orotate decreases the inhibitory effect of ethanol on galactose elimination in perfused rat liver. Biochem J 160:715-720

9. Isselbacher KJ 1957 Evidence for an accessory pathway of galactose metabolism in mammalian liver. Science 126:652-654

10. Greene HL, Wilson FL, Hefferan P, Terry AB, Morn JB, Slonin AE, Clause TH 1978 ATP depletion, a possible role in the pathogenesis of hyperuricemia in glycogen storage disease type I. J Clin Invest 62:321-328

11. van den Berghe G, Bronfman M, Vaneste R, Hers HG 1977 The mechanism of ATP depletion in the liver after a load of fructose. A kinetic study of liver adenylate deaminase. Biochem J 162:601-609

12. Oberhaensli RD, Rajagopalan B, Taylor DJ, Radda GK, Collins JE, Leonard JV 1988 Study of liver metabolism in glucose-6-phosphatase deficiency (glycogen storage disease type 1A) by P-31 magnetic resonance spectroscopy. Pediatr Res 23:375-380 